Indonesian Journal of Medicine (2018), 3(3): 146-150

https://doi.org/10.26911/theijmed.2018.03.03.04

\title{
Effect of Cardiac Rehabilitation on NT-Pro BNP, METS, and Quality of Life, in Patients with Coronary Artery Disease after Undergoing Percutaneous Coronary Intervention
}

\author{
Noer Rachma \\ Department of Physical Medicine and Rehabilitation, Dr. Moewardi Hospital, Surakarta
}

\begin{abstract}
Background: Percutaneous coronary intervention (PCI) is one of the most effective therapies in patients with coronary artery disease (CAD) after the attack. Cardiac rehabilitation (CR) makes an important contribution to secondary prevention of cardiac events. The World Health Organization defines CR as the sum of activities required to influence favorably the underlying cause of the disease, as well as to ensure the best possible physical, mental and social conditions, so that they may, by their own efforts, preserve or resume when lost as normal a place as possible in the life of the community. This study aimed to estimate the effects of CR on NT-proBNP and METs among patients with CAD after PCI.

Subjects and Method: This was a cohort study carried out at Dr. Moewardi Hospital, Surakarta, Central Java, from November to February 2018. A sample of 18 patients with CAD after PCI was selected for this study. The dependent variables were NT-proBNP, METs, and quality of life. The independent variable was $\mathrm{CR}$. The three outcome variables were measured before and after CR. The data before and after CR were compared and tested by t-test.

Results: NT-proBNP level in CAD patients after PCI (Mean $=97.17 \mathrm{ng} / \mathrm{ml})$ was lower than before PCI (Mean=1,629.4 ng/ml), and it was statistically significant. METS value in CAD patients after PCI $($ Mean $=8.31 \mathrm{ml} / \mathrm{kg})$ was higher than before PCI $($ Mean $=6.41 \mathrm{ml} / \mathrm{kg})$, and it was statistically significant. The quality of life also increased significantly.

Conclusion: Cardiac rehabilitation is effective to lower NT-proBNP level, as well as to increase METS value and quality of life of CAD patients.
\end{abstract}

Keywords: coronary artery disease, cardiac rehabilitation, NT-proBNP, METs, quality of life

\section{Correspondence:}

Noer Rachma. Department of Physical Medicine and Rehabilitation, Dr. Moewardi Hospital, Surakarta, Central Java.

\section{BACKGROUND}

One of the most invasive therapies performed in post-attack Coronary Artery Disease (CAD) patients or acute coronary syndrome is percutaneous coronary intervention or known as percutaneous coronary syndrome (PCI). This action can eliminate blockages immediately, so that blood flow can become normal again so that damage to the heart muscle can be avoided (Silber et al., 2005).

After percutaneous coronary intervention, patients should continue to carry out planned activities and exercises. This is because like the whole muscle, the heart muscle also requires exercise. Activities that only sit on a chair or only pay attention to the surrounding environment will not provide exercise to the heart so that the heart's strength does not increase. According to VIHA Cardiac Risk Reduction \& Rehabilitation Activity and Exercise Guide for Heart Patients Rehabilitation programs in the initial 6 weeks greatly affect overall rehabilitation (Vancouver Island Health Authority, 2011).

The important cardiac rehabilitation was performed in coronary post-interven- 
tion CAD patients, namely 6-minutes walking test and treadmill. Treadmills are one of the advanced aerobic exercises recommended in patients after percutaneous coronary intervention. With this exercise the heart's ability to pump blood will increase and the resting heart rate will decrease (AACVPR, 2013).

The cardiovascular response will affect consumption of VO2 max consumption as a fitness index to measure the level of cardiorespiratory health. VO2 max will affect the value of metabolic equivalents (METs) and also affect the quality of life of CAD patients after percutaneous coronary intervention.

Repair of heart conditions can also be assessed through markers including NTproBNP. NT-proBNP is a stable part of pro BNP which is a hormone produced when the ventricular muscles of the heart stretch or experience pressure. If the heart, especially the left ventricular muscles of the heart function is impaired, then the level of NT-proBNP in the blood will increase [4]. Therefore, NT-proBNP is often used as a marker for detection of heart failure.

Because of the importance of cardiac rehabilitation in people with $\mathrm{CHD}$ after percutaneous coronary intervention, the researchers conducted a study to determine the effect of cardiac rehabilitation on NTproBNP levels, METs values and quality of life of CAD patients after percutaneous coronary intervention.

\section{SUBJECTS AND METHOD}

A cohort study was carried out on CAD patients after percutaneous coronary intervention at the cardiac polyclinic, Dr Moewardi Hospital, Surakarta, from November 2017 - February 2018.

The study sample was percutaneous coronary artery postoperative CAD patients based on reports of stent placement with exclusion criteria including unstable angina, resting systolic $\mathrm{BP}>200 \mathrm{~mm} \mathrm{Hg}$ or diastolic rest $>100 \mathrm{mmHg}$, orthostatic hypotension $=20 \mathrm{mmHg}$, moderate to severe aortic stenosis, disorders systemic acute or fever, ventricular dysrhythmias or uncontrolled atria, sinus tachycardia ( $>120$ beats/ min), uncontrolled congestive heart disorder, Ventricular Atrio block, myocarditis and active pericarditis, embolism, thromboplebitis, ST wave changes $(>3 \mathrm{~mm})$, uncontrolled diabetes, orthopedic problems that interfere rest.

The study variables specified include; (1) independent variable was cardiac rehabilitation (2) dependent variable (NT-pro BNP, METS value, and quality of life).

Analysis of the effect of independent variables on dependent variables was by using different tests of statistical data analysis on the results of the first observation compared to the results of the second observation.

\section{RESULTS}

The study objects consisted of 18 samples were measured twice on the three variables that were affected, namely the first measurement was carried out before the cardiac rehabilitation (pre) and the second was done after cardiac rehabilitation (post).

Descriptions of the characteristics of age, sex, activity and cardiac stent installation status were summarized in Table 1.

Testing the effect of cardiac rehabilitation on NT-proBNP, METs and Quality of Life can be proven by testing different 2 (two) average of the three variables before and after cardiac rehabilitation. Testing the data normality of NT-proBNP, METs, and Quality of Life variables using the Shapiro Wilks data normality test (see Table 2).

The results of the three data normality data testing can be concluded in the following Table 2. 
Indonesian Journal of Medicine (2018), 3(3): 146-150

https://doi.org/10.26911/theijmed.2018.03.03.04

Table 1. Descriptions of the characteristics of age, sex, and activity

\begin{tabular}{lcc}
\hline \multirow{2}{*}{ Quantitative Variable } & \multicolumn{2}{c}{ Parameter } \\
\cline { 2 - 3 } Age (year): & $\begin{array}{c}54.89 \\
\text { Total }\end{array}$ & Mean \\
Sex: & 16 & 7.95 \\
Man & 2 & 88.9 \\
Woman & & 11.1 \\
Activity (Proportion): & 4 & \\
Laborer & 3 & 22.2 \\
Private employee & 3 & 16.7 \\
Pensioner & 4 & 16.7 \\
- Entrepreneur & 2 & 22.2 \\
- Employee-Teacher & 2 & 11.2 \\
- Others & & 11.1 \\
Cardiac stent installation status & 13 & 72.2 \\
- Completed vascularization & 5 & 27.8 \\
- Incompleted revasvascularization & & \\
\hline
\end{tabular}

Table 2. Test the normality of NT-proBNP variable data, METs, and quality of life before and after cardiac rehabilitation

\begin{tabular}{ccccccc}
\hline \multirow{2}{*}{ Variable } & \multirow{2}{*}{ Group } & \multicolumn{2}{c}{ Parameter } & Normality Data Test & \\
\cline { 3 - 7 } & & Mean & SD & Statistic SW & p & Result \\
\hline \multirow{2}{*}{ NT-proBNP } & Pre & 1629.83 & 2129.36 & 0.641 & 0.001 & AN \\
& Post & 971.17 & 1064.00 & 0.797 & 0.001 & AN \\
METs & Pre & 6.41 & 2.52 & 0.929 & 0.168 & N \\
& Post & 8.31 & 2.29 & 0.954 & 0.495 & N \\
Quality of life & Pre & 120.61 & 14.18 & 0.905 & 0.071 & N \\
& Post & 129.11 & 11.69 & 0.920 & 0.128 & N \\
\hline
\end{tabular}

Note: $\mathrm{N}=$ Normal, $\mathrm{AN}=$ Abnormal

It appears in the results of the data normality test of the research variables that the NT-proBNP variable is the only variable that has abnormal data distribution both before cardiac rehabilitation and after cardiac rehabilitation. While the variable METs and Quality of Life, both have normal data distribution both for prior cardiac rehabilitation and after cardiac rehabilita- tion. Thus the difference test is 2 (two) mean NT-proBNP variables before and after cardiac rehabilitation using the Wilcoxon test. While the difference test 2 (two) mean variables METs and the variable of Quality of Life before and after cardiac rehabilitation are each using $t$ test for paired samples.

Table 3. Difference t-test 2 mean NT-pro BNP variables, METs, and quality of life before and after cardiac rehabilitation

\begin{tabular}{ccllllll}
\hline & \multicolumn{2}{c}{ Pre } & \multicolumn{2}{c}{ Post } & \multicolumn{2}{c}{ Difference t-test 2 mean } \\
\hline Variable & Mean & \multicolumn{1}{c}{ SD } & \multicolumn{1}{c}{ Mean } & \multicolumn{1}{c}{ SD } & \multicolumn{1}{c}{ Statistic value } & \multicolumn{1}{c}{ p } \\
\hline NT-pro BNP & 1629.83 & 2129.36 & 971.17 & 1064.0 & $\mathrm{Z}=-2.07$ & 0.039 \\
METs & 6.41 & 2.52 & 8.31 & 2.29 & $\mathrm{t}=-4.36$ & 0.001 \\
Quality of life & 120.61 & 14.18 & 129.11 & 11.69 & $\mathrm{t}=-2.33$ & 0.032 \\
\hline
\end{tabular}

If further detailed based on cardiac stent installation status in patients, the results of different tests 2 (two) NT-proBNP variable mean before and after cardiac rehabilitation can be summarized in the table 4 . 
Table 4. Different t-tests 2 mean NT-pro BNP variables, METs, and quality of life before and after cardiac rehabilitation based on cardiac stent installation status

\begin{tabular}{ccc}
\hline \multirow{2}{*}{ Variable } & \multicolumn{2}{c}{$\mathbf{p}$} \\
\cline { 2 - 3 } & Completed Vascularization & Incompleted Revascularizaton \\
\hline NT-proBNP & 0.129 & 0.027 \\
METs & 0.005 & 0.006 \\
\hline
\end{tabular}

Different test results 2 (two) paired sample mean of NT-ProBNP variable found that the average before cardiac rehabilitation was 1.629 .36 with a standard deviation of 2.129.36 and after rehabilitation the heart decreased to an average of 971.17 with a standard deviation of 1,064.0. Both of these averages differ convincingly at a significance level of 5 percent $(\mathrm{p}<0.05)$. Thus, cardiac rehabilitation reduces levels of NT-proBNP levels in CAD patients after percutaneous coronary intervention.

Different test results 2 The sample mean variable value of METs found that the average before cardiac rehabilitation was 6.41 with a standard deviation of 2.52 and after rehabilitation the heart increased to an average of 8.31 with a standard deviation of 2, 29. Both of these averages differ convincingly at a significance level of 5 percent $(\mathrm{p}<0.05)$. Thus, rehabilitation increases the METs value in CAD patients after percutaneous coronary intervention.

Different test results 2 (two) mean until paired on the quality of life variable found that the average before cardiac rehabilitation was 120.61 with a standard deviation of 14.18 and after rehabilitation the heart decreased to an average of 129.11 with standard deviation of 11.69. Both of these averages differ convincingly at a significance level of 5 percent ( $\mathrm{p}<0.05)$. Thus Cardiac Rehabilitation can improve the quality of life of CAD patients after percutaneous coronary intervention.

\section{DISCUSSION}

The effectivity of implementing cardiac rehabilitation in coronary heart patients after percutaneous coronary intervention can be determined through several indicators including NT-proBNP level, METS value, and quality of life. In this study, cardiac rehabilitation caused a decrease in NT-proBNP levels, an increase in METS values, and a significant improvement in quality of life in patients.

Significant reductions in NT-pro BNP levels are significant in coronary heart disease. In a study conducted by Charlotte (2005) on the effect of NT-proBNP levels on the death of patients with coronary heart disease in the long term, it was stated that high levels of NT-pro BNP were found in patients with coronary heart disease who died, while survivors were found in NT- low level proBNP. The significant decrease in NT-Pro BNP levels after the implementation of cardiac rehabilitation shows the effectiveness of cardiac rehabilitation and provides an overview of the patient's life expectancy.

The METS value in this study also increased significantly from 6.41 to 8.31 (p $<0.05$ ). According to the New York Heart Association Functional Classification of Heart Failure, a METS value of more than 4.5 does not indicate a limitation of physical activity. Patients can perform normal activities without having to experience an increase in heart rate, shortness of breath, or severe fatigue. Patients have also been able to carry out activities such as mopping the floor, shelves, hanging clothes, light exercise, playing volleyball, swimming, and dancing slowly. The higher the 
METS value, the patient is able to perform heavier activities.

Besides NT-proBNP and METS, improving quality of life is one indicator of the effectiveness of cardiac rehabilitation. Quality of life is one's expectation of life compared to the reality of life it faces. With an improved quality of life, patients will be more positive and enthusiastic in living life. In the results of this study, the quality of life of patients increased significantly ( $p$ $<0.05$ ). The results of this study are similar to research conducted by Artur et al., (2002), Dalal et al., (2007), and Jolly et al., (2009) who stated that cardiac rehabilitation is effective in improving the quality of life of patients.

Based on the results of this study, it can conclude that cardiac rehabilitation involves decreasing NT-proBNP levels, increasing METS values, and improving the quality of life for coronary heart disease patients after percutaneous coronary intervention.

From this results, the author suggest that cardiac rehabilitation has an effect on decreasing NT-proBNP levels, METS values, and quality of life of patients after percutaneous coronary intervention. Therefore, cardiac rehabilitation should be carried out continuously in percutaneous coronary post intervention patients.

Further research on the mechanism of cardiac rehabilitation against cardiovascular response and other indicators is needed to strengthen the benefits of implementing cardiac rehabilitation for patients with coronary heart disease after percutaneous coronary intervention.

\section{REFERENCE}

AACVPR (2013). Guideline for cardiac rehabilitation and secondary prevention programs. $5^{\text {th }}$ edition. USA: Human Kinetics.
Arthur H, Smith K, Kodis J, McKelvie R (2002). A controlled trial of hospital versus home-based exercise in cardiac patients. Medicine \& Science in Sports \& Exercise. 34(10): 1544-1550.

Charlote et al. (2005). N-Terminal Pro-BType-Natriuretic Peptide and LongTerm Mortality ins Stable Coronary Heart Disease. N Engl J Med. 352: 666-675.

Dalal H, Evans P, Campbell J, Taylor R, Watt A, Read K, Mourant A, Wingham J, Thompson D, Pereira GD (2007). Home-based versus hospitalbased rehabilitation after myocardial infarction: a randomised trial with preference arms - Cornwall Heart Attack Rehabilitation Management Study (CHARMS). International Journal of Cardiology. 119(2): 202-211.

Jolly K, Lip G, Taylor R (2009). The Birmingham rehabilitation uptake maximization study (BRUM): a randomised controlled trial comparing home-based with controlled trial comparing home-based with centrebased cardiac rehabilitation. Heart. 95(1): 36- 42.

Silber S, Albertsson P, Aviles FF et al. (2005). Guidelines for percutaneous coronary interventions. Eur Heart J. 26:804-847.

Spanaus KS and Eckardstein A. Natriuretic peptides in cardiac and renal failure. Pipette Swiss Laboratory Medicine 2007: 6; 6-11

Vancouver Island Health Authority (VIHA). Activity and exercise guide for heart patients. Heart Health Program. 2011 http://www.viha.ca/NR/rdonlyres/5 A962352-299E-4FDA-865B-F3930E861B76/o/activity_guide_after_heart_attack_angina_stent_angioplasty_v13.pdf diakses Februari 2018. 